\title{
Phototoxic Effect of Visible Blue Light on Porphyromonas Gingivalis and Aggregatibacter Actinomycetemcomitans
} \author{
Al Sharani ${ }^{3}$ \\ ${ }^{1}$ Department of Conservative Dentistry and Oral Health, Sana'a University, Republic of Yemen \\ ${ }^{2}$ Medical Microbiology and Clinical Immunology, Sana'a University, Republic of Yemen \\ ${ }^{3}$ Oral Medicine and Periodontology Department, University of Sciences and Technology, Yemen
}

Mohsen Ali Al Hamzi ${ }^{1}$, Ayman Ahmed Ahmed Al jorany ${ }^{2}$, Hassan A Al-Shamahy ${ }^{2 *}$ and Amani Abdulhakeem

*Corresponding author: Prof Hassan A Al-Shamahy, Medical Microbiology and Clinical Immunology, Faculty of Medicine and Health Sciences, Sana'a University, Republic of Yemen.

Received Date: October 17, 2019

Published Date: November 18, 2019

\section{Abstract}

Background: Chronic gingivitis is a common disease, especially among adult patients who often develop periodontal pocket and the occurrence gradual loss of the periodontal attachment. A wide range of microorganisms is known to be associated with periodontal disease, including Porphyromonas gingivalis ( $\mathrm{Pg}$ ) and Aggregatibacter actinomycetemcomitans (Aa).

Objectives: Therefore, a study was conducted to determine the effect of phototoxicity of visible blue light (vBL) on Aa and Pg Clinical isolates from chronic periodentitis patients, and to study their antibiotic sensitivity against selected antibiotics.

Methods: The test was carried out on 15 strains of Aa and 15 strains of Pg isolated from pockets of chronic periodentitis patients aged between 30-50 years old with pocket depths of 5-6mm. Bacteria cultured, isolated, identified by standard bacteriological methods, and then exposed to visible blue light for different periods of time. After bacterial cultures were exposed to light, bacterial killing rates were calculated from a colony forming unit (CFU) after 48 hours of anaerobic incubation.

Results: There was a decrease in CFU for both microorganisms and the result is increased with the increase of exposure to vBL, from zero, 20, 40 and 60 secs.

Conclusion: There was a phototoxic effect of visible blue light emitted by a light therapy device against anaerobic gingival pathogens and exposure to blue light is effective in reducing gum pathogens. It is recommended to use an adjuvant external optical enhancer and to expose pathogens to visible light for clinical antimicrobial treatment.

Keywords: Blue light; CFU; Anaerobic periodontal pathogen

\section{Introduction}

The result of vBL in the $400-450 \mathrm{~nm}$ range has been reported in a number of studies as it has been effective as a topical treatment for eczema and psoriasis and is assumed to help inhibit the immune response [1-3]. Studies have also shown improvement in facial acne when exposed to LED emissions at $414 \mathrm{~nm}$ [4,5]. A combination of red and blue light exposure is used in clinical dermatological treatments [6,7]. Creators such as Philips are currently developing devices and technologies that emit a blue visible spectrum for use in the treatment of skin diseases [8-10]. The presence of blue light has also been reported in a number of studies that have been effective in killing bacteria associated with periodontal disease, such as Pg and Aa [11-13] Periodontal disease, also known as gum disease, is a group of inflammatory conditions that affect the tissues surrounding the teeth [14]. The disease start as acute tenderness of the gum tissue and untreated cases can develop to form dental pockets, and finally tooth death [14]. Wide group of microorganisms have been associated with periodontal disease, out of which Pg and Aa. Treatment of periodontal disease has long involved non-surgical cleaning of the gums under a procedure called "root surface instrumentation" (RSI), which causes mechanical 
disruption of the bacterial biofilms below the gums. It makes it difficult to completely remove bacterial deposits and biofilms from the root surface by mechanical methods [15]. Also, there have been many treatment options available to support the effectiveness of the instrumentation, such as the use of local antibiotics and antimicrobials-photodynamic therapy [16].

One of the problems that address the use of chemical agents is the failure to maintain therapeutic concentrations at the target site and the disruption of oral microflora [17]. Thus, photodynamic therapy (PTD) was introduced to open a new course in the treatment of periodontal disease without hindering the above obstacles and problems. An innovative non-antibiotic approach, the blue light antimicrobial in the spectrum of $400-470 \mathrm{~nm}$ demonstrated its intrinsic antimicrobial properties resulting from the presence of endogenous photosynthetic chromophores in pathogenic microbes. Microbes are expected to be less able to develop resistance to blue light than conventional antibiotics, due to the multi-target properties of blue light (aBL) [11]. In addition, it is well accepted that aBL is less harmful to host cells than UVC irradiation. $[12,13]$. The objectives of this study were to determine the phototoxic effect of visible blue light on Pg and Aa isolates of chronic gingivitis patients, and to study their antibiotic sensitivity against selected antibiotics.

\section{Materials and Methods}

\section{Sampling}

Fifteen healthy patients between the ages of 30 and 50 participated in this study. They had chronic gingivitis with at least one pocket of a depth of 5-6mm. A part of plaque was drilled from the gum pocket without touching adjacent tissue. The plaque sample was spread over the solid blood agar supplied with selective material in the plates and then the plates were transferred to an anaerobic jar for anaerobic incubation for 72 hours. After incubation, the bacterial identity was determined (microscopic shape, colonial shape and size, gram stain, biochemical tests and antibiotic sensitivity. Pg colonies were a convex round colony, clearly marked by the presence of black pigmentation. They were gram-negative with a rod-shaped microscope, negative catalyze, and urease, and had a weaker activity of haemolysis, sensitive to metronidazole and clindamycin. The colonies were again cultured on the same anaerobic media for 72 hours under the same condition, using the same method, to obtain pure cultures from both Aa and Pg. The colonies showed Aa convex appearance of white stars with no black pigmentation. Gram-negative were with the appearance of rod form under the microscope, positive catalyze, negative coagulase, negative urease, had beta-haemolysis activity and were resistant to metronidazole and clindamycin but sensitive to kanamycin.

\section{Blue light exposure}

After incubation, a serial dilution procedure was performed to standardize the amount of bacteria using 106 as the primary bacterial concentration, and to reduce the number of colonies to one countable. A standard volume of Thioglycolate broth, which is a liquid medium used to breed bacteria containing anaerobic agents for dispersion in each 96 -well $(150 \mu \mathrm{l})$, then an individual colony for each microorganism mixed in a broth well was selected well. We followed the dilution rate at 1:10 until we reached the fifth dilution. Four dishes were prepared from solid blood agar-enriched media for each bacterium. The broth is taken from the fifth well on each plate and then subjected to different periods of exposure, the beam of light from the blue light is directed on the plate, starting from zero/second (no exposure) for the first plate, then 20, 40, 60 for the second and fourth plate respectively; the light treatment tip was standardized with the center of the light beam directed towards the center of the plate for all experiments. Visible blue light emitted by commercially available light curing (LED curing light); emitting blue light (400-500nm) of $1000 \mathrm{mw}$ of power. Bacterial killing rates from the colony forming unit (CFU) were calculated after 48 hours of anaerobic incubation after exposure to light. FU was calculated by direct visibility by counting the total number of colonies on day 13. The plate with no exposure (zero second sets) for each organism looked at the control plate in which we compared the results of the remaining three plates. The entire procedure was repeated for each of the 15 samples of patients who participated in the study.

\section{Results}

It is very obvious that the values of CFU decreased significantly $(p=0.001)$ as the time of exposure difference increased between groups until reaching the highest value when the difference was 60 seconds. There was significance effect of visible blue light on the CFU of anaerobic periodontal pathogens Aggregatibacter actinomycetemcomitans in-vitro at different light exposure time. There was increase in the inhibition of growth in which the inhibition rates for $20 \mathrm{sec}$ exposure, $40 \mathrm{sec}$ exposure and $60 \mathrm{sec}$ exposure were $41.2 \%, 54.2 \%$, and $64.5 \%$ respectively. Also, there was decrease of Mean $\pm \mathrm{SD}$ of $\mathrm{CFU}$ as we proceed from A: zero seconds of light exposure, B:20S, C:40S and D:60S [305.6 \pm 36.9 to $179.7 \pm 18.6(20 \mathrm{~S}), 140 \pm 15.9(40 \mathrm{~S})$ and $108.6 \pm 13.8(60 \mathrm{~S})]$. In intergroup comparison CFU of the bacteria at each period of light exposure time was compared to the CFU at all the periods of light exposure. There was a high significant statistical difference between the control group (had no light exposure) and the 60 second group ( $p=0.001$ ) (Tables $1-4)$ shows the phototoxic effect of visible blue light on the CFU of anaerobic periodontal pathogens Pg at separate vBL exposure time. It is very obvious that the values of CFU decreased significantly $(\mathrm{p}<0.001)$ as the time of exposure difference increased between groups until reaching the highest value when the difference was 60 seconds. By comparing with zero exposure, the inhibition rates for 20sec exposure, $40 \mathrm{sec}$ exposure and 60 sec exposure were 22.04\%,35.4\%, and 49.7\% respectively. Also, there was decrease of Mean \pm SD of CFU as we proceed from A: zero seconds of light exposure, B:20S, C:40S and D:60S $(236.8+28.8$ at zero time to $184.6 \pm 14.7,153.1 \pm 15.4$, and $119 \pm 9$ respectively). 
Table 1: The phototoxic effect of visible blue light on the CFU of anaerobic periodontal pathogens Aggregatibacter actinomycetemcomitans at different light exposure time.

\begin{tabular}{|c|c|c|c|c|}
\hline \multirow{2}{*}{ CFU Values } & \multicolumn{5}{|c|}{ Time of Exposure (sec) } \\
\cline { 2 - 5 } & Zero & $\mathbf{2 0} \mathbf{~ s e c}$ & $\mathbf{4 0} \mathbf{~ s e c}$ & $\mathbf{6 0 ~} \mathbf{~ s e c}$ \\
\hline Mean & 305.6 & 179.7 & 140.1 & 108.6 \\
\hline Variance & 1366.6 & 346 & 253.6 & 190.6 \\
\hline Standard division & 36.9 & 18.6 & 15.9 & 13.8 \\
\hline Standard Error & 9.5 & 4.8 & 4.11 & 3.5 \\
\hline Minimum & 208 & 140 & 102 & 80 \\
\hline Maximum & 370 & 210 & 165 & 125 \\
\hline Median & 305 & 180 & 143 & 110 \\
\hline Mode & 300 & 190 & 130 & 100 \\
\hline Sum & 4584 & 2696 & 2101 & 1629 \\
\hline Student Test & 32 & 37.4 & 30.4 & 30.4 \\
\hline P value & $<0.001$ & $<0.001$ & $<0.001$ & $<0.001$ \\
\hline Inhibition Growth Rate & Ref & $41.20 \%$ & $54.20 \%$ & $64.50 \%$ \\
\hline
\end{tabular}

Table 2: The significance of the phototoxic effect of visible blue light on the mean \pm SD CFU of anaerobic periodontal pathogens Aggregatibacter actinomycetemcomitans at different light exposure time.

\begin{tabular}{|c|c|c|c|}
\hline $\begin{array}{c}\text { Time of } \\
\text { Exposure (sec) }\end{array}$ & $\begin{array}{c}\text { CFU of Tested } \\
\text { Bacteria Mean } \pm \text { SD }\end{array}$ & $\mathbf{X}^{\mathbf{2}}$ & P value \\
\hline Control (Zero) & $305.6 \pm 36.9$ & \multicolumn{2}{|c|}{ Reference } \\
\hline $20 \mathrm{sec}$ & $179.7 \pm 18.6$ & 12.02 & 0.002 \\
\hline $40 \mathrm{sec}$ & $140 \pm 15.9$ & 16.2 & 0.0007 \\
\hline $60 \mathrm{sec}$ & $108.6 \pm 13.8$ & 19.79 & 0.0003 \\
\hline
\end{tabular}

Table 3: The phototoxic effect of visible blue light on the CFU of anaerobic periodontal pathogens Porphyromonas gingivalis at different light exposure time.

\begin{tabular}{|c|c|c|c|c|}
\hline \multirow{2}{*}{ CFU Values } & \multicolumn{4}{|c|}{ Time of Exposure (sec) } \\
\cline { 2 - 5 } & Zero & $\mathbf{2 0 ~ s e c}$ & $\mathbf{4 0 ~ s e c}$ & $\mathbf{6 0} \mathbf{~ s e c}$ \\
\hline Mean & 236.8 & 184.6 & 153 & 119 \\
\hline Variance & 832.1 & 218 & 237.2 & 81 \\
\hline Standard division & 28.8 & 14.7 & 15.4 & 9 \\
\hline Standard error & 7.4 & 3.8 & 3.9 & 2.3 \\
\hline Minimum & 200 & 168 & 130 & 100 \\
\hline Maximum & 317 & 215 & 180 & 135 \\
\hline Median & 230 & 185 & 153 & 120 \\
\hline Mode & 210 & 170 & 130 & 120 \\
\hline Sum & 3552 & 2769 & 2295 & 1786 \\
\hline Student Test & 31.8 & 48.3 & 38.4 & 51.2 \\
\hline P value & $<0.001$ & $<0.001$ & $<0.001$ & $<0.001$ \\
\hline Inhabitation Growth Rate & Ref & $22.04 \%$ & $35.40 \%$ & $49.70 \%$ \\
\hline
\end{tabular}

Table 4: The significance of the phototoxic effect of visible blue light on the mean $\pm S D$ CFU of anaerobic periodontal pathogens Porphyromonas gingivalis at different light exposure time.

\begin{tabular}{|c|c|c|c|}
\hline $\begin{array}{c}\text { Time of } \\
\text { Exposure (sec) }\end{array}$ & $\begin{array}{c}\text { CFU of Tested } \\
\text { Bacteria } \\
\text { Mean } \pm \text { SD }\end{array}$ & $\mathbf{X}^{2}$ & P value \\
\hline Control (Zero) & $236.8 \pm 28.8$ & \multicolumn{2}{|c|}{ Reference } \\
\hline $20 \mathrm{sec}$ & $184.6 \pm 14.7$ & 6.3 & 0.01 \\
\hline $40 \mathrm{sec}$ & $153 \pm 15.4$ & 10.16 & 0.004 \\
\hline $60 \mathrm{sec}$ & $119 \pm 9$ & 15.5 & 0.001 \\
\hline
\end{tabular}

\section{Discussion}

In the current study there was significance effect of visible blue light on the CFU of anaerobic periodontal pathogens Aa invitro at different vBL exposure time in culture media in which the inhibition rates for $20 \mathrm{sec}$ exposure, $40 \mathrm{sec}$ exposure and 60 sec exposure were $41.2 \%, 54.2 \%$, and $64.5 \%$ respectively in comparing with zero exposure time (Table 1). Also, the Mean \pm SD of CFU were significantly decreased from $305.6 \pm 36.4$ at zero time to $179.7 \pm 18.6(20 \mathrm{sec}), 140.1 \pm 15.9$ (40 sec), and $108.6 \pm 13.8$ (60 sec) respectively (Table 2 ). These results confirmed the toxic effect of visible blue light on Aa. This effect can be explained by the fact that the function of external light transformers is to absorb visible light that matches the wavelength of peak absorption, and then to cause a photochemical mechanism that kills bacteria [18-20]. The results of the current study are similar to those reported by Henry et al, [20]. Visible blue light has been shown to have toxic effects on Porphyromonas, Prevotella species [21,22], and similar effects were observed when visible light was used against gum Porphyromonas gingivalis and Fusobacterium nucleatum [23]. The findings regarding $P$. gingivalis were also consistent with a study conducted in Korea but in disagreement with the same study as far as the results of Aa were not found as any significant phototoscopic effect of visible blue light against Aa. They also found that there is a toxic effect of visible blue light emitted by the source of a light halogen therapy device on planktonic anaerobic gingival pathogens [10]. A significant statistical difference was observed in the CFU comparison of Aa at different periods of exposure to vBL, as well as a significant statistical difference in comparison of CFU of Pg at different periods of exposure to vBL. This means more exposure time leads to more bacterial death. This can be explained by the decrease of bacterial CFU for both Aa and Pg directly with the period of exposure to blue light curing. Low bacterial CFU is also explained by the killing ability of light and temperature against these bacteria. Kariam and René found vBL (408-750nm) in 2009 to be intrusive and cause damage to the metabolism and membranes of bacteria [24].

In addition, light sources have significantly stronger effects with reactive oxygen radicals occurring jointly with normal light converters, such as humic acid or protoporfirin. It has also been found that bacterial enzyme synthesis such as Super Oxide Dismutase and bacterial catalyze have been shown to decrease independently with the effects of light [24]. The results of the current study clearly indicate that the effect of blue light exposure increases as the exposure time increases, the greater the blue light exposure difference between the groups, the greater the difference between CFU, the best results were obtained when there was a difference (60 seconds), and the comparison results were significant in both organisms. In conclusion, there was a phototoxic effect of visible blue light emitted by a light therapy device against anaerobic gum pathogens. Moreover, one of the advantages of PDT as a visible blue light is its safety, as confirmed by Dai et al. $[25,26]$, Ramakrishnan et al. [27], Zhang Y et al. [28]. They showed that 
under some exposures, there were no cytotoxic or gene-toxic effects on the relevant host cells. In addition, no evidence of genotoxicity of visible blue light ( $\mathrm{aBL}$ ) was observed in mouse skin in vivo when subjected to therapeutic exposure to aBL for inactivating mature biofilms [29].

\section{Conclusion}

In the conclusions, there was a phototoxic effect of visible blue light emitted by a light therapy device against anaerobic gingival pathogens and exposure to blue light is effective in reducing gum pathogens. It is recommended to use an exogenous photo sensitizer and that pathogens are exposed to visible light for clinical antimicrobial treatment.

\section{Acknowledgment}

The authors would like to acknowledge Faculty of Dentistry, Sana'a University and the Microbiology Department of the National Center of Public Health Laboratories (NCPHL) Sana'a, Yemen for support and provided working space and materials.

\section{Conflict of Interest}

No conflict of interest associated with this work.

\section{Author's Contribution}

This research work is part of MSc thesis. The candidate is the second author (AAA) who conducted the works and the experiments and wrote up the thesis. The corresponding author (HAA) supervised the experimental work, revised and edited the thesis draft and the manuscript. (MAA) was co-advisor of the work and $(\mathrm{AA})$ helped in dental works and laboratory works.

\section{References}

1. Glazer Hockstein C, Dunaief JL (2006) Could blue light-blocking lenses decrease the risk of age-related macular degeneration. Retina 26(1): 1-4.

2. Weinstabl A, Hoff Lesch S, Merk HF, Von Felbert V (2011) Prospective randomized study on the efficacy of blue light in the treatment of psoriasis vulgaris. Dermatology 223(3): 251-259.

3. Pfaff S, Liebmann J, Born M, Merk HF, Von Felbert V (2015) Prospective Randomized Long-Term Study on the Efficacy and Safety of UV-Free Blue Light for Treating Mild Psoriasis Vulgaris. Dermatology 231(1): 24-34.

4. Gold MH, Andriessen A, Biron J, Andriessen H (2009) Clinical Efficacy of Self-applied Blue Light Therapy for Mild-to-Moderate Facial Acne. J Clin Aesthet Dermatol 2(3): 44-50.

5. Morton CA, Scholefield RD, Whitehurst C, Birch J (2005) An open study to determine the efficacy of blue light in the treatment of mild to moderate acne. J Dermatolog Treat 16(4): 219-223.

6. Wan MT, Lin JY (2014) Current evidence and applications of photodynamic therapy in dermatology. Clin Cosmet Investing Dermatol 7: $145-163$.

7. Nestor MS, Swenson N, Macri A, Manway M, Paparone P (2016) Efficacy and Tolerability of a Combined $445 \mathrm{~nm}$ and $630 \mathrm{~nm}$ Over-the-counter Light Therapy Mask with and without Topical Salicylic Acid versus Topical Benzoyl Peroxide for the Treatment of Mild-to-moderate Acne Vulgaris. J Clin Aesthet Dermatol 9(3): 25-35.

8. Margrain TH, Boulton M, Marshall J, Sliney DH (2004) Do blue light filters confer protection against age-related macular degeneration? Prog Retin Eye Res 23(5): 523-531.

9. (2007) Recommended Practice for Photobiological Safety for Lamp and Lamp Systems-General Requirements. American National Standard Institute/Illuminating Engineering Society of North America.
10. Hyun Hwa Song, Jae Kwan Lee, Heung Sik Um, et al. (2013) Phototoxic effect of blue light on the planktonic and biofilm state of anaerobic periodontal pathogens. J Periodontal Implant Sci 43(2): 72-78.

11. Dai T, Gupta A, Murray CK, Vrahas MS, Tegos GP, Hamblin MR (2012) Blue light for infectious diseases: Propionibacterium acnes, Helicobacter pylori, and beyond? Drug Resist Updat 15: 223-236.

12. Kleinpenning MM, Smits T, Frunt MH, Van Erp PE, Van De Kerkhof PC, Gerritsen RM (2010) Clinical and histological effects of blue light on normal skin. Photo dermatol photo-immunol photo med 26: 16-21.

13. Liebmann J, Born M, Kolb Bachofen V (2010) Blue-light irradiation regulates proliferation and differentiation in human skin cells. J Invest Dermatol 130: 259-269.

14. Kah Yan How KY, Song KP, Chan KG (2016) Porphyromonas gingivalis: An Overview of Periodontopathic Pathogen below the Gum Line. Front Microbiol 7: 53-62.

15. Fontana CR, Abernethy AD, Som S, Ruggiero K, Doucette S, et al. (2009) The antibacterial effect of photodynamic therapy in dental plaquederived biofilms. J Periodontal Res 44: 751-759.

16. Berakdar M, Callaway A, Fakhr Eddin M, Roß A, Willershausen B (2012) Comparison between scaling-root planning (SRP) and SRP/ photodynamic therapy: six-month study. Head Face Med 8: 1-12.

17. Takasaki AA, Aoki A, Mizutani K, Schwarz F, Sculean A, et al. (2009) Application of antimicrobial photodynamic therapy in periodontal and peri-implant diseases. Periodontol 51: 109-140.

18. Sharman WM, Allen CM, Van Lier JE (1999) Photodynamic therapeutics: basic principles and clinical applications. Drug Discov Today 4: 507-517.

19. Maisch T, Szeimies RM, Jori G, Abels C (2004) Antibacterial photodynamic therapy in dermatology. Photochem Photobiol Sci 3: 907-917.

20. Maisch T (2007) Anti-microbial photodynamic therapy: useful in the future? Lasers Med Sci 22: 83-91.

21. Henry CA, Judy M, Dyer B, Wagner M, Matthews JL (1995) Sensitivity of Porphyromonas and Prevotella species in liquid media to argon laser. Photochem Photobiol 61: 410-413.

22. Henry CA, Dyer B, Wagner M, Judy M, Matthews JL (1996) Photo-toxicity of argon laser irradiation on biofilms of Porphyromonas and Prevotella species. Journal of Photochemistry and Photobiology B: Biology 34: 123128.

23. Feuerstein 0, Persman N, Weiss EI (2004) Phototoxic effect of visible light on Porphyromonas gingivalis and Fusobacterium nucleatum: an in vitro study. Photo-chem Photobiol 80: 412-415.

24. Karim E, René S (2009) A comparative study of the photo-inactivation of bacteria by meso-substituted cationic porphyrin, rose Bengal and methylene blue. Desalination 246(1-3): 353-362.

25. Dai T, Gupta A, Huang YY, Sherwood ME, Murray CK, et al. (2013a) Blue light eliminates community-acquired methicillin-resistant Staphylococcus aureus in infected mouse skin abrasions. Photomed Laser Surg A 31: 531-538.

26. Dai T, Gupta A, Huang YY, Yin R, Murray CK, et al. (2013b) Blue light rescues mice from potentially fatal Pseudomonas aeruginosa burn infection: efficacy, safety, and mechanism of action. Antimicrob Agents Chemother 57: 1238-1245.

27. Ramakrishnan P, Maclean M, MacGregor SJ, Anderson JG, Grant MH (2016) Cytotoxic responses to $405 \mathrm{~nm}$ light exposure in mammalian and bacterial cells: Involvement of reactive oxygen species. Toxicology in vitro: an international journal published in association with BIBRA 33: 54-62.

28. Zhang Y, Zhu Y, Gupta A, Huang Y, Murray CK, et al. (2014) Antimicrobial blue light therapy for multidrug-resistant Acinetobacter baumannii infection in a mouse burn model: implications for prophylaxis and treatment of combat-related wound infections. J Infect Dis 209: 19631971.

29. Wang Y, Wu X, Chen J, Amin R, Lu M, et al. (2016) Antimicrobial Blue Light Inactivation of Gram-Negative Pathogens in Biofilms: In Vitro and In Vivo Studies. J Infect Dis 213: 1380-1387. 